\title{
BMJ Open Effect of cardiovascular prevention strategies on incident coronary disease hospitalisation rates in Spain; an ecological time series analysis
}

\author{
María José Medrano, Enrique Alcalde-Cabero, Cristina Ortíz, Iñaki Galán
}

To cite: Medrano MJ, Alcalde-Cabero E, Ortíz C, et al. Effect of cardiovascular prevention strategies on incident coronary disease hospitalisation rates in Spain; an ecological time series analysis. BMJ Open 2014;4: e004257. doi:10.1136/ bmjopen-2013-004257

- Prepublication history and additional material for this paper is available online. To view these files please visit the journal online (http://dx.doi.org/10.1136/ bmjopen-2013-004257).

Received 15 October 2013 Revised 13 December 2013 Accepted 9 January 2014

CrossMark

National Centre for Epidemiology, Carlos III Institute of Health, Madrid, Spain

Correspondence to Dr María José Medrano; pmedrano@isciii.es

\section{ABSTRACT}

Objective: To assess the overall population impact of primary prevention strategies (promotion of healthy lifestyles, prevention of smoking and use of vascular risk drug therapy) of coronary disease in Spain.

Design: Ecological time series analysis, 1982-2009.

Setting: All public and private hospitals in Spain.

Participants: General population.

Outcome: Incident coronary disease hospitalisation as derived from official hospital discharge data.

Methods: Annual hospitalisation rates were modelled according to nationwide use of statins,

antihypertensive, antidiabetic and antiplatelet drugs, and prevalences of smoking, obesity and overweight. Additive generalised models and mixed Poisson regression models were used for the purpose, taking year as the random-effect variable and adjusting for age, sex, prevalence of vascular risk factors and the number of hospital beds in intensive and coronary care units.

Results: Across 28 years and 671.5 million personyears of observation, there were 2986834 hospitalisations due to coronary disease; of these, 1441980 (48.28\%) were classified as incident. Hospitalisation rates increased from 1982 to 1996 , with an inflection point in 1997 and a subsequent $52 \%$ decrease until 2009. Prevalences of smoking, obesity, overweight and use of vascular risk drug therapy were significantly associated with hospitalisation rates $(\mathrm{p}<0.001)$ : incidence rates ratios $(95 \% \mathrm{Cl})$ for the fourth versus the first quartile were 1.46 (1.42 to $1.50), 1.80$ (1.78 to 1.83 ), 1.58 (1.55 to 1.60 ) and 0.57 ( 0.51 to 0.63$)$, respectively. These variables accounted for $92 \%$ of interannual variability.

Conclusions: After decades of continuous rises, hospitalisation due to incident ischaemic heart disease has been cut by half, an achievement associated with the decline in smoking and the increase in vascular risk drug therapy. These results indicate that these two primary prevention strategies have been effective at a population level, thanks to an appropriate balance between financial and health goals, something that should be left intact despite the current economic crisis. Future strategies ought to lay special stress on excessive body weight prevention.

\section{Strengths and limitations of this study}

- The study shows that the decline in coronary disease in Spain was associated with the exponential increase in pharmacological treatment of vascular risk, together with the decline in active smoking that followed the strong interventions against tobacco use implemented in mid-1990s and late 1990s. This decrease in ischaemic heart disease hospitalisation rates could have been even greater, had it not been for the frequency of excessive weight, which not only failed to decline but actually rose.

- The exposure-effect associations found: (1) are of great magnitude; (2) show a strong doseresponse relationship; (3) show a correct temporality; (4) are biologically plausible and (5) are consistent with similar studies in other countries, with trends in other tobacco-related diseases and with the increase in the rates of detection, treatment and control of vascular risk factors in Spain.

- The results are relevant as some of these measures (ie, broad use of statins in general population) are still controversial. Moreover, the results may substantially affect public health policy, especially in a context of financial crisis.

- This is an ecological study based on health indicators and targeted at the assessment of public health; its results should not be interpreted as outcomes of intervention trials, even though they may nuance the latter insofar as they provide an illustration of their external validity.

\section{INTRODUCTION}

Ischaemic heart disease (IHD) is a severe disease, is lethal in its acute form in $20-30 \%$ of cases ${ }^{1}$-indeed, it is the leading cause of death in men and the second leading cause of death in women in Spain ${ }^{2}$ - and is chronically incapacitating in a great proportion of survivors. Its frequency in the Spanish population is high, with population incidence being estimated at 207 and 45/100 000 in 
men and women, respectively, and hospitalisation 140000 cases annually. ${ }^{3}$ Consequently, this situation became a public health priority and the target of specific health-planning strategies at a national level. ${ }^{4}$

The main vascular risk factors (excessive body weight, smoking habit, hypercholesterolaemia, arterial hypertension and diabetes mellitus) can be modified by changes in lifestyle or therapeutic interventions. In recent years, cardiovascular disease prevention has, therefore, been the focus of a major collective effort, in which health professionals as well as scientific societies, the pharmaceutical industry and health administrations have all taken part. The pillars of IHD prevention have been prevention of smoking, promotion of healthy lifestyles, and detection, treatment and medical control of arterial hypertension, hypercholesterolaemia, diabetes mellitus and platelet aggregation in high-risk patients. ${ }^{4}{ }^{5}$ These strategies have been generally implemented throughout the Spanish National Health System, as a result of recommendations made by the respective health authorities, ${ }^{4}$ prevention guidelines drawn up by experts and scientific societies, both domestic and international, ${ }^{5-7}$ and the development of risk functions which not only enable patients to be stratified according to their individual coronary risk, estimated on the basis of vascular risk factors taken jointly, ${ }^{8}$ but also serve as a guide when it comes to making therapeutic decisions about controlling vascular risk.

The promotion of healthy habits has specifically centred on diet and physical exercise. ${ }^{10}$ Prevalence of obesity and overweight is regarded as an indicator of inadequate diet and physical activity. ${ }^{41}$ With respect to smoking, the impact of antismoking interventions on coronary risk has been comprehensively described at an individual and a population level. Hence, assessment of epidemiological antismoking legislation in a number of countries has shown its effectiveness in terms of IHD mortality and morbidity. ${ }^{12}{ }^{13}$ Finally, the use of cardiovascular disease prevention drug therapy in healthy persons has demonstrated its effectiveness at an individual level in many clinical trials, though it is not known whether this effectiveness has been reflected at a population level, that is, its epidemiological impact. Clinical trials are conducted under controlled experimental conditions and the patients included are selected on the basis of strict inclusion and exclusion criteria. Consequently, such studies do not represent the general population and their results may possibly not be seen at a population level (external validity). ${ }^{14}$

To our knowledge, there is no study that has assessed the joint impact of these cardiovascular disease prevention measures on IHD incidence. Epidemiological studies undertaken in different countries, ${ }^{15-20}$ including Spain, ${ }^{21}$ have linked the decrease in cardiovascular and IHD mortality to the decline in population levels of vascular risk factors. In Spain, $50 \%$ of the reduction in coronary mortality is estimated to be due to changes in risk factors, essentially total cholesterol (close on $31 \%$ of the fall in mortality) and systolic blood pressure (15\%). ${ }^{21}$ Most of these studies have, however, been based on IMPACT methodology, ${ }^{17} 18$ which was designed to assess changes in mortality but has not been adapted to the task of assessing morbidity. Recent studies in the $\mathrm{USA}^{22}{ }^{23}$ Italy $^{24}$ and Australia ${ }^{25}$ have reported a decrease in IHD-related hospital morbidity, which was linked to antismoking legislation and the use of cardioprotective medication, though these associations were not statistically proved. Finally, a recent population-based observational study in Israel ${ }^{26}$ assessed the effect of continued use of statins on the incidence of acute infarction and coronary revascularisation but did not consider the effect of use of antihypertensive, antiplatelet or antidiabetic drugs.

Accordingly, the aim of this study was to describe the time trend in hospital incident-IHD-related morbidity rates and assess the impact of smoking prevention, promotion of healthy lifestyles and the use of cardiovascular disease prevention drug therapy, using the following as indicators: population prevalence of smoking; prevalence of obesity and overweight and use of statins and antihypertensive, antiplatelet and antidiabetic drugs.

\section{METHODS}

We conducted an epidemiological assessment study on the impact of preventive measures, using regression analysis and time-series modelling and, for study purposes, included the total Spanish population over 29 years of age. The period considered in the description of the time series was 1982-2009, avoiding the years preceding the entry into force of the International Classification of Diseases, 9th Revision, Clinical Modification (ICD-9-CM). In the analysis of related factors, the series was restricted to the period 1996-2006, since this was the period for which data on all the explanatory variables were available.

\section{Principal and secondary variables \\ Data sources}

The outcome variable was frequency of hospitalisation due to incident IHD (ICD-9-CM codes 410-414, with four digits), expressed in descriptive analyses in the form of annual age-adjusted rates according to the Standard European Population. Data on hospital discharges due to this cause were drawn from anonymised MBDS microfiches (Minimum Basic Data Set/Conjunto Minimo Básico de Datos, the official nation-wide administrative and statistical database which includes clinical and demographic data on every hospital discharge, obtained from the pertinent medical records), and were completed with a patient discharge sample from some private hospitals that were not included in the MBDS. The fiches were supplied by the National Statistics Institute (NSI) (Instituto Nacional de Estadística) under a data loan agreement containing an undertaking of confidentiality and respect for statistical secrecy. Population 
data for calculating the rates for each year, sex and age group were obtained from NSI intercensal estimates. The age strata were 5-year age groups starting from 30 to 85 and older.

An incident event was defined as that in which the following two conditions were fulfilled: (1) diagnosis at discharge of acute IHD, acute myocardial infarction, intermediate coronary syndrome (unstable angina) or angina pectoris (ICD 410,411 or 413) and (2) first admission due to IHD, as shown by a check for duplicate entries based on the fields, 'sex', 'date of birth' and 'province of residence'. Events for which control for duplicates could not be performed for lack of any record of the patient's complete date of birth $(n=91176$, $3.1 \%$ ) were excluded.

The method used to control for duplicates was validated by comparing the results against data on 30205 hospitalisations in eight cities for which patient identification codes were available, yielding a sensitivity of $97.88 \%$ and specificity of 88.73 . The distribution by age, sex and diagnostic category of this validation sample did not differ from that of the study population.

The variables considered as potentially explanatory of the trend in IHD hospitalisation rates in the population were:

Use of statins (atorvastatin, cerivastatin, fluvastatin, lovastatin, pravastatin and simvastatin);

Use of antihypertensive drugs (angiotensin II receptor antagonists, ACE inhibitors, $\beta$-blockers, diuretics, calcium channel blockers and others);

Use of platelet aggregation inhibitors (aspirin, carbasalate, clopidogrel, dipyridamol, citazol, ticlopidine and triflusal); Use of antidiabetic drugs (insulins, biguanides, sulfonylureas, $\alpha$-glucosidase inhibitors, thiazolidinediones and combinations of these).

The use of these drugs was expressed in Defined Daily Doses (DDDs) per 1000 inhabitants per day (DHDs), for the period 1996-2006. These data were drawn from reports issued by the Spanish Medications \& Health Products Agency on the basis of data on packages dispensed under and charged to the National Health System. ${ }^{27}$ The methodology used is described in detail in these publications. DHDs divided by 10 were introduced into the models, with the estimators having to be interpreted as the effect for every increase of 10 units in DHD.

Prevalence, with a breakdown by year, sex and age, of smoking, overweight, obesity, arterial hypertension, hypercholesterolaemia and diabetes mellitus obtained from self-report data in the 1987,1993, 1995, 1997, 2001, 2003 and 2006 National Health Surveys, ${ }^{28}$ with data for the intermediate years being estimated by means of linear interpolation of data for the pivotal years.

Number of physically available hospital beds in intensive care and coronary care units per 1000 inhabitants. $^{28}$
Data analysis

Weightings specified by the NSI were used for the calculation of the number of cases. In descriptive analyses, age-adjusted incident IHD hospitalisation rates (Standard European Population) were calculated for each year and sex. These rates were depicted graphically, as were the frequency measures of the remaining explanatory variables for each year.

The effect of the explanatory variables on incident IHD morbidity was estimated on the basis of incidence rates ratios (IRRs) derived from mixed Poisson regression models of fixed and random effects, with year being introduced as the random-effect variable, using the command 'xtmepoisson' implemented in Stata, that fits mixed-effects models for count responses assuming a Poisson distribution of the data.This approach enables one to control for temporal autocorrelation and overdispersion, measure interannual variability explained by the preventive measures and minimise the risk of residual confounding. The dependent variable was the number of incident hospitalisations in each sex and age stratum, and the national population figure of each stratum was introduced as the exposed population. This is equivalent to modelling of rates. The explanatory variables were sequentially introduced, successively obtaining age-adjusted and sex-adjusted estimators and multivariate estimators. We considered the concurrent effect across time of the explanatory variables and hospitalisation, plus the effect with lags of 1,2 and 3 years, so as to take into account the possible latency between exposure and its effect, and assess the temporality of the associations.

The effect of drug therapy for control of vascular risk was analysed for each type of drug (statins, antihypertensive, antiplatelet and antidiabetic drugs), individually and jointly, using the variable 'drug use for control of vascular risk' obtained by adding together the respective usages of each type to avoid the strong collinearity that characterises the consumption of such drugs (correlation coefficients of 0.97 to 0.99 ). The explanatory variables categorised in quartiles were included in the models for dose-response analysis. These models were used to measure the interannual variability explained by the variables, calculated as 1 minus the ratio between the variance of the random term in the complete model and the variance of the random term in the model without prevention explanatory variables and in the model adjusted for age and sex.

Finally, the incidence time series was analysed and plotted graphically with the aid of Poisson nonparametric generalised additive models (GAMs) implemented in the mgcv library of the $\mathrm{R}$ statistical package V.2.15.0 (30 March 2012) ${ }^{29}$ GAM models allow to graphically depict the relationship including smoothing and a non-parametric fit, with no a priori assumptions on the actual relationship between response and predictor. As time is used as the predictor, the result is a smoothed time series of the response. The rates were modelled 
and smoothed by reference to time, and the smoothed age-adjusted and sex-adjusted series were depicted graphically. The explanatory variables were subsequently included in these models to depict the trends not due to these variables.

(See technical appendix in supplementary material for theoretical basis of models and technical details.)

\section{RESULTS}

Across the 28 years and 671.5 million person-years of observation, there were 2986834 hospitalisations in Spain due to IHD; and of these, 1441980 (66.7\% men and $33.3 \%$ women), accounting for $48.28 \%$ of the total, were classified as incident. The mean age at admission was $65.9 \pm 12.8$ years, with a higher frequency in the 60 74-year age group $(41.9 \%)$. Diagnosis at discharge was acute infarction in 55\%, unstable angina in $14.7 \%$ and stable angina in $30.3 \%$ of cases. Women's mean age was 5 years older $(\mathrm{p}<0.001)$ than men, and the over 74 -year age group was far more frequent among women than among men (data not shown).

The annual age-adjusted incident IHD hospitalisation rates per 100000 , which are depicted graphically in figure 1, show a rise from 1982 to 1996 , a sharp inflection in 1997 and a subsequent cumulative decrease of $52 \%$ until 2009 (53.5\% and $49.6 \%$ in men and women, respectively). The decline was constant throughout the period, with a slight increase in 2000 , coinciding with the change in the definition of IHD. The distribution by sex of the incidence rates changed across the study period, with a decrease in the male/female ratio from 3.3 to 2.4 .

Of the total study period (1982-2009), data on indicators of cardiovascular disease prevention (prevalence of smoking, prevalence of obesity and overweight and use of drug therapy for control of vascular risk) were available for the period 1996-2006. These years witnessed a rise in the use of statins $(948.9 \%)$ and antihypertensive $(95.4 \%)$, antiplatelet $(105 \%)$ and antidiabetic drugs $(142 \%)$ and a decline in smoking prevalence $(6.8 \%$ in women and $23.8 \%$ in men). Prevalence of obesity increased by $40 \%$ (table 1 and figure 1 ).

Consumption of statins and antihypertensive, antiplatelet and antidiabetic drugs, individually considered, displayed an inverse and statistically significant relationship with incident IHD hospitalisation rates in models adjusted for age, sex and prevalences of smoking, obesity and overweight (table 2), and this association became progressively greater when growing lags were taken into account. Similarly, the use of drugs considered jointly was inversely associated (IRR $0.97,95 \%$ CI 0.97 to 0.98 ) with IHD incidence. The greater magnitude of the effect of drug use when considered individually rather than jointly should not be construed as a discrepancy: instead, this is attributable to the difference in scale and to drug associations and the lack of adjustment among the individual drug usages due to collinearity. In contrast, prevalence of smoking, obesity and overweight was positively associated with incidence of hospitalisation due to IHD. In the models in which adjustment was additionally made for prevalences of arterial hypertension, hypercholesterolaemia and diabetes mellitus, and for the number of physically available beds in intensive and coronary care units, the above associations were not substantially modified, that is, the effect of frequency of smoking was not modified, the effect of frequency of obesity and overweight was slightly attenuated and the inverse association with drug use was slightly accentuated, when the respective types of drugs were considered individually and when they were considered jointly.

Furthermore, these associations displayed a statistically significant dose-response relationship in the models adjusted for sex, age, the variables in the table and year as a random-effect variable (table 3): whereas the IRR of smoking prevalence in the fourth versus the first quartile was 1.46 (95\% CI 1.42 to 1.50$)$ and the IRRs for prevalence of obesity and overweight were 1.80 (1.78 to 1.83) and 1.58 (1.55 to 1.60$)$, respectively, and the IRR for cardiovascular disease prevention drug therapy was 0.57 (0.51 to 0.63$)$. The linear trend was statistically significant for all four variables. The protective effect of cardiovascular disease prevention drug therapy was slightly attenuated when the growing lags between exposure and effect were taken into account (IRR lag $0=0.57$ ( 0.51 to 0.63 )/ IRR lag $3=0.61$ ( 0.57 to 0.66$)$ ). Similarly, while the association with prevalence of overweight was attenuated over time, the association was not modified when the growing lags between exposure and effect for prevalences of obesity and smoking habit were taken into account.

The interannual variability in hospitalisation rates explained by the models considering the four variables simultaneously (continuous scale) was: $92 \%$ for no lag between exposure and effect; $95 \%$ for a lag of 1 year; $97 \%$ for a lag of 2 years and $94 \%$ for a lag of 3 years (data not shown in tables). The proportion of variability in annual rates explained by prevention variables raised from $92 \%$, with respect to the empty model, to $97 \%$ when calculated with respect to the model adjusted by age and sex, thus meaning a $5 \%$ variability in hospitalisation rates due to changes in age-sex population structure from 1996 to 2006.

Finally, figure 2 describes the time series of incidence analysed using Poisson non-parametric generalised additive models. The left plot displays the downward trend in the annual age-adjusted and sex-adjusted incidence rates, which shows very narrow CI because of the very large size of the study population. This downward trend disappeared after additionally adjusting for the four explanatory variables (figure 2, right plot), which shows that the decrease was due to the effect of these same variables. From 2004 onwards, however, the declining trend remained in evidence even after adjustment was made for use of preventive drug therapy and prevalence of smoking, obesity and overweight. 
Statins (DDD/1000)

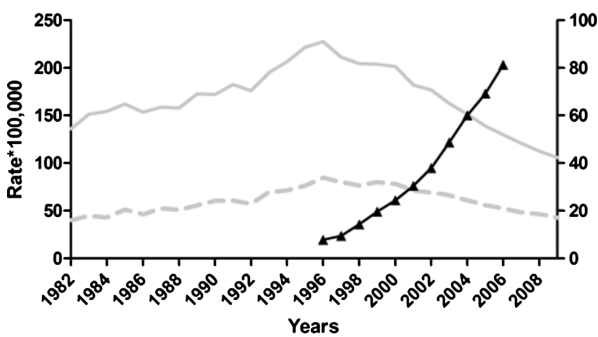

Antiplatelet drugs (DDD/1000)

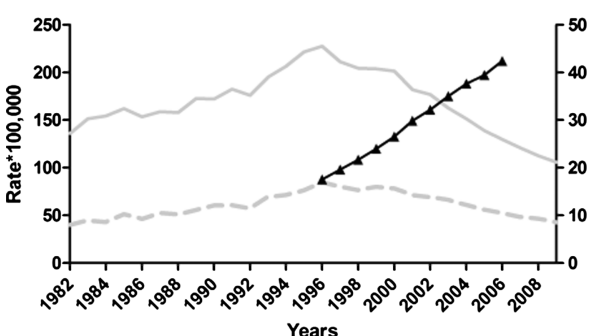

Medication drugs (DDD/1000)

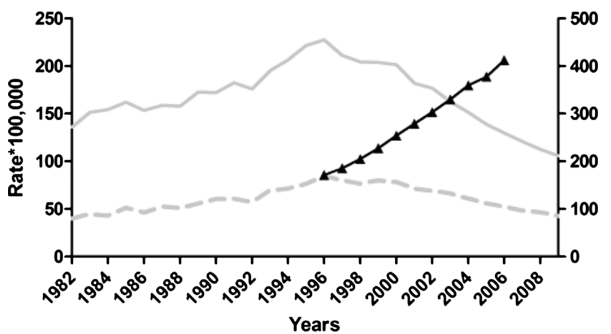

Obesity (\%)

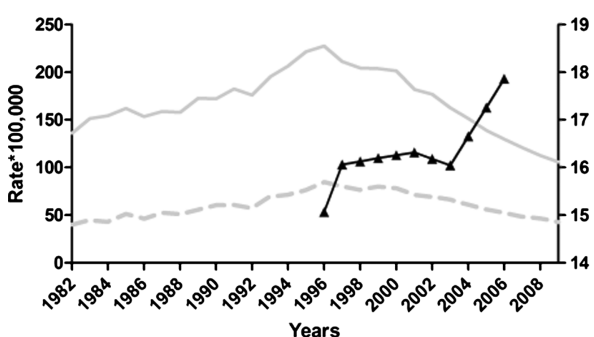

Antihypertensive drugs (DDD/1000)

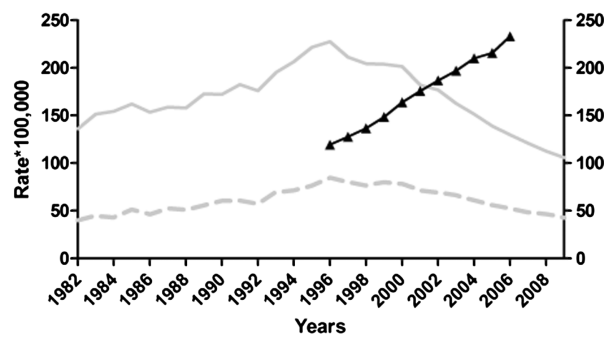

Antidiabetic drugs (DDD/1000)

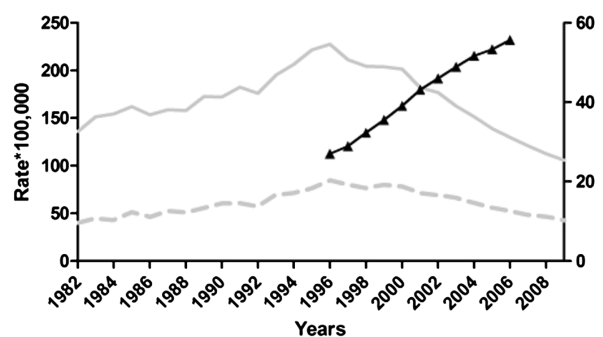

Smoking prevalence (\%)

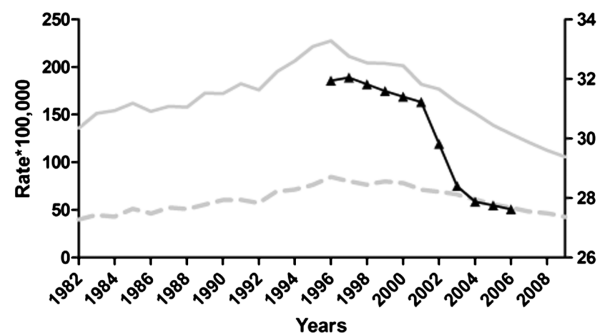

Overweight (\%)

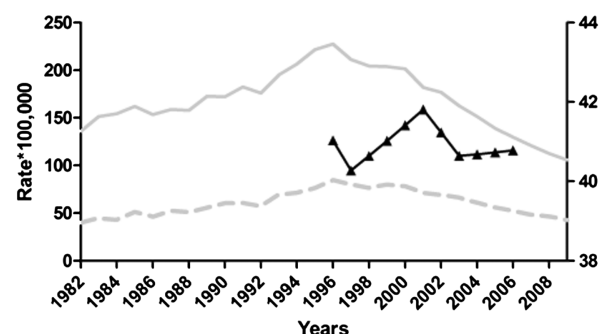

- IHD age-adjusted rate. Men - IHD age-adjusted rate. Women DDD: Defined daily dose

Figure 1 Annual trends in explanatory variables and incident ischaemic heart disease hospitalisation rates.

\section{DISCUSSION}

The results show that, after decades of continuous rises, hospitalisation due to incident IHD in the Spanish adult population fell after 1997, a drop that was associated with the decline in smoking and, in equal measure, with the increase in pharmacological treatment of vascular risk. This decrease in IHD hospitalisation rates could have been even greater, had it not been for the frequency of excessive weight, which not only failed to decline but actually rose. Overall, the factors analysed accounted for over $90 \%$ of the decrease in incident IHD hospitalisation rates. The decline occurred despite the increased sensitivity of diagnostic tests and the ensuing change in the IHD-definition criteria. ${ }^{30}$

The accuracy of the results is reinforced because the associations show a strong dose-response relationship and a correct temporality, with the effect being maintained in response to growing lags between exposure and disease. The associations found are biologically plausible, since the role of smoking in the aetiology of 
Table 1 Annual trends in explanatory variables in Spanish general population

\begin{tabular}{|c|c|c|c|c|c|c|c|c|c|c|c|}
\hline & 1996 & 1997 & 1998 & 1999 & 2000 & 2001 & 2002 & 2003 & 2004 & 2005 & 2006 \\
\hline Proportion (\%) Smokers & 31.9 & 32.0 & 31.8 & 31.6 & 31.4 & 31.2 & 29.8 & 28.4 & 27.9 & 27.8 & 27.6 \\
\hline Proportion (\%) Obesity & 15.1 & 16.1 & 16.1 & 16.2 & 16.3 & 16.3 & 16.2 & 16.0 & 16.7 & 17.3 & 17.9 \\
\hline Proportion (\%) Overweight & 41.0 & 40.3 & 40.6 & 41.0 & 41.4 & 41.8 & 41.2 & 40.6 & 40.7 & 40.7 & 40.8 \\
\hline $\begin{array}{l}\text { Drugs for control of vascular risk } \\
\text { Number of Defined Daily Doses* per } \\
1000 \text { inhabitants per day }(\times 10) \text {. Total }\end{array}$ & 171.5 & 185.6 & 204.9 & 227.7 & 253.8 & 279.2 & 303.0 & 329.7 & 359.6 & 377.7 & 412.3 \\
\hline Statins & 7.8 & 9.4 & 14.3 & 19.7 & 24.4 & 30.4 & 38.0 & 48.7 & 60.1 & 69.2 & 81.3 \\
\hline Antihypertensive drugs & 119.2 & 127.6 & 136.6 & 148.4 & 163.8 & 175.7 & 186.9 & 197.1 & 210.2 & 215.7 & 232.9 \\
\hline Antidiabetic drugs & 27.0 & 28.9 & 32.3 & 35.6 & 39.1 & 43.2 & 46.0 & 48.9 & 51.7 & 53.3 & 55.7 \\
\hline Antiplatelet drugs & 17.5 & 19.6 & 21.7 & 24.0 & 26.6 & 29.9 & 32.2 & 35.0 & 37.6 & 39.5 & 42.4 \\
\hline
\end{tabular}

coronary disease and the effect of drugs on vascular risk have been sufficiently proved by in vitro studies and clinical trials. Finally, the results are in line with: what has been published with respect to the decreases in IHD mortality ${ }^{15-21}$ and hospital morbidity recorded in other countries $^{22-26}$; the decline in the incidence of smoking-related diseases such as asthma and lung cancer in Spain $^{28}$; the reduction in mean population levels of serum cholesterol and systolic blood pressure ${ }^{21}$ and the increase in the rates of detection, treatment and control of vascular risk as documented by cross-sectional studies on the Spanish population. ${ }^{31}$
The study shows the success of the smoking control strategies implemented in the $1990 \mathrm{~s},{ }^{32}$ based on legislative measures targeted at restricting the sale, raising the price and placing limitations on the advertising of cigarettes, information programmes about smoking-related risks and antismoking campaigns. These measures were followed by a considerable decline in the frequency of active smoking, principally among light and moderate smokers. ${ }^{28}$ The most recent legislative measures, aimed at preventing passive smoking, have not achieved such a marked decrease in active smoking prevalence. Our results suggest, however, that part of the decline in IHD

Table 2 Effect of prevalence of smoking habit, obesity, overweight and use of cardiovascular disease prevention drug therapy on annual incident ischaemic heart disease hospitalisation rates 1996-2006

\begin{tabular}{|c|c|c|c|c|c|c|c|c|}
\hline & \multicolumn{2}{|l|}{ Lag0 } & \multicolumn{2}{|l|}{ Lag1 } & \multicolumn{2}{|c|}{ Lag2 } & \multicolumn{2}{|c|}{ Lag3 } \\
\hline & $\overline{I R R}$ & $95 \% \mathrm{Cl}$ & IRR & $95 \% \mathrm{Cl}$ & IRR & $95 \% \mathrm{Cl}$ & IRR & $95 \% \mathrm{Cl}$ \\
\hline \multicolumn{9}{|c|}{ Adjustment for age, sex, year (random variable) and specified variables } \\
\hline Smokers (\%) & 1.02 & (1.01 to 1.02$)$ & 1.02 & (1.02 to 1.02$)$ & 1.02 & (1.02 to 1.02$)$ & 1.02 & (1.02 to 1.02$)$ \\
\hline Obesity (\%) & 1.05 & (1.04 to 1.05$)$ & 1.05 & (1.05 to 1.05$)$ & 1.05 & (1.05 to 1.05$)$ & 1.06 & (1.05 to 1.06$)$ \\
\hline Overweight (\%) & 1.04 & (1.04 to 1.04$)$ & 1.04 & (1.04 to 1.04$)$ & 1.03 & (1.03 to 1.04$)$ & 1.03 & (1.03 to 1.03 ) \\
\hline Drug use $\left(\times 10 \mathrm{DHDs}^{\star}\right) \dagger$ & 0.97 & (0.97 to 0.98$)$ & 0.97 & (0.97 to 0.97$)$ & 0.97 & (0.97 to 0.97 ) & 0.97 & (0.96 to 0.97$)$ \\
\hline Statinst & 0.92 & (0.91 to 0.93 ) & 0.91 & (0.90 to 0.92$)$ & 0.90 & (0.88 to 0.91 ) & 0.87 & (0.85 to 0.90$)$ \\
\hline Antihypertensive drugs $†$ & 0.95 & (0.94 to 0.95$)$ & 0.94 & (0.94 to 0.95$)$ & 0.94 & (0.94 to 0.94$)$ & 0.93 & (0.93 to 0.94$)$ \\
\hline Antidiabetic drugs† & 0.81 & (0.79 to 0.83 ) & 0.81 & (0.79 to 0.83 ) & 0.80 & (0.79 to 0.81 ) & 0.78 & (0.77 to 0.79$)$ \\
\hline Antiplatelet drugst & 0.77 & (0.76 to 0.79$)$ & 0.77 & (0.75 to 0.79$)$ & 0.75 & (0.74 to 0.77 ) & 0.72 & (0.70 to 0.74$)$ \\
\hline \multicolumn{9}{|l|}{ Multivariate adjustment $\ddagger$} \\
\hline Smokers (\%) & 1.01 & (1.01 to 1.01$)$ & 1.02 & (1.01 to 1.02$)$ & 1.02 & (1.02 to 1.02$)$ & 1.02 & (1.02 to 1.02$)$ \\
\hline Obesity (\%) & 1.03 & (1.03 to 1.03$)$ & 1.03 & (1.03 to 1.04$)$ & 1.03 & (1.03 to 1.04 ) & 1.03 & (1.03 to 1.04$)$ \\
\hline Overweight (\%) & 1.03 & (1.03 to 1.03$)$ & 1.03 & (1.03 to 1.03$)$ & 1.03 & (1.02 to 1.03$)$ & 1.03 & (1.03 to 1.03$)$ \\
\hline Drug use $\left(\times 10 \mathrm{DHDs}^{\star}\right) \dagger$ & 0.96 & (0.96 to 0.97$)$ & 0.96 & (0.96 to 0.97$)$ & 0.96 & (0.96 to 0.96$)$ & 0.96 & (0.96 to 0.96$)$ \\
\hline Statins $†$ & 0.90 & (0.89 to 0.91$)$ & 0.89 & (0.88 to 0.90$)$ & 0.87 & (0.86 to 0.89 ) & 0.85 & (0.83 to 0.87$)$ \\
\hline Antihypertensive drugs† & 0.92 & (0.91 to 0.93$)$ & 0.92 & (0.91 to 0.93 ) & 0.92 & (0.92 to 0.93 ) & 0.92 & (0.92 to 0.93$)$ \\
\hline Antidiabetic drugst & 0.73 & (0.68 to 0.77$)$ & 0.74 & (0.71 to 0.77 ) & 0.75 & (0.73 to 0.77 ) & 0.75 & (0.74 to 0.75$)$ \\
\hline Antiplatelet drugs $†$ & 0.70 & (0.66 to 0.73 ) & 0.70 & (0.67 to 0.73 ) & 0.70 & (0.68 to 0.71 ) & 0.68 & (0.67 to 0.70$)$ \\
\hline
\end{tabular}

Models for exposure-effect lags of $0,1,2$ and 3 years.

*DHDs: Number of Defined Daily Doses per 1000 inhabitants per day.

†Not adjusted among themselves because collinearity.

$\ddagger$ Adjusted for variables specified in the table plus age, sex, year of discharge as a random-effect variable, prevalence (\%) of arterial hypertension, prevalence (\%) of hypercholesterolaemia, prevalence (\%) of mellitus diabetes and the number of hospital beds in intensive care and coronary care units. 
Table 3 Dose-response analysis of the effect of prevalence of smoking habit, obesity, overweight and use of cardiovascular disease prevention drug therapy on incident ischaemic heart disease hospitalisation rates

\begin{tabular}{|c|c|c|c|c|c|c|c|c|}
\hline & \multicolumn{2}{|l|}{ Lag0 } & \multicolumn{2}{|l|}{ Lag1 } & \multicolumn{2}{|l|}{ Lag2 } & \multicolumn{2}{|l|}{ Lag3 } \\
\hline & IRR $^{*}$ & $95 \% \mathrm{Cl}$ & $\mathbf{I R R}^{*}$ & $95 \% \mathrm{Cl}$ & IRR $^{*}$ & $95 \% \mathrm{Cl}$ & IRR $^{*}$ & $95 \% \mathrm{Cl}$ \\
\hline \multicolumn{9}{|l|}{ Smokers (\%) } \\
\hline 1st quartile & 1.00 & & 1.00 & & 1.00 & & 1.00 & \\
\hline 2nd quartile & 0.92 & (0.91 to 0.93 ) & 0.91 & (0.90 to 0.93$)$ & 0.92 & (0.91 to 0.94$)$ & 0.93 & (0.91 to 0.94$)$ \\
\hline 3rd quartile & 1.23 & (1.21 to 1.25$)$ & 1.21 & (1.19 to 1.23$)$ & 1.20 & (1.18 to 1.22$)$ & 1.18 & (1.15 to 1.20$)$ \\
\hline 4th quartile & 1.46 & (1.42 to 1.50$)$ & 1.48 & (1.44 to 1.52$)$ & 1.50 & (1.46 to 1.55$)$ & 1.49 & (1.45 to 1.54$)$ \\
\hline $\begin{array}{l}P \text { trend } \\
\text { Obesity (\%) }\end{array}$ & $<0.001$ & & $<0.001$ & & $<0.001$ & & $<0.001$ & \\
\hline 1st quartile & 1.00 & & 1.00 & & 1.00 & & 1.00 & \\
\hline 2nd quartile & 1.46 & (1.44 to 1.47 ) & 1.45 & (1.43 to 1.46$)$ & 1.34 & (1.33 to 1.36$)$ & 1.32 & (1.30 to 1.33 ) \\
\hline 3rd quartile & 1.71 & (1.69 to 1.73 ) & 1.65 & (1.63 to 1.67$)$ & 1.53 & (1.51 to 1.55$)$ & 1.48 & (1.46 to 1.50$)$ \\
\hline 4th quartile & 1.80 & (1.78 to 1.83 ) & 1.82 & (1.79 to 1.85 ) & 1.75 & (1.73 to 1.79 ) & 1.86 & (1.78 to 1.90$)$ \\
\hline $\begin{array}{l}\mathrm{P} \text { trend } \\
\text { Overweight }(\%\end{array}$ & $<0.001$ & & $<0.001$ & & $<0.001$ & & $<0.001$ & \\
\hline 1st quartile & 1.00 & & 1.00 & & 1.00 & & 1.00 & \\
\hline 2nd quartile & 1.23 & (1.22 to 1.24$)$ & 1.21 & (1.19 to 1.22$)$ & 1.14 & (1.13 to 1.16$)$ & 1.06 & (1.05 to 1.08 ) \\
\hline 3rd quartile & 1.41 & (1.39 to 1.43 ) & 1.35 & (1.33 to 1.37$)$ & 1.30 & (1.28 to 1.31$)$ & 1.22 & (1.20 to 1.24$)$ \\
\hline 4th quartile & 1.58 & (1.55 to 1.60$)$ & 1.50 & (1.47 to 1.52$)$ & 1.43 & (1.41 to 1.45$)$ & 1.33 & (1.31 to 1.36$)$ \\
\hline $\mathrm{P}$ trend & $<0.001$ & & $<0.001$ & & $<0.001$ & & $<0.001$ & \\
\hline \multicolumn{9}{|c|}{ Use of drugs ( $\times 10$ DHDs $†$ ) } \\
\hline 1st quartile & 1.00 & & 1.00 & & 1.00 & & 1.00 & \\
\hline 2nd quartile & 0.85 & (0.76 to 0.93$)$ & 0.87 & (0.80 to 0.94$)$ & 0.83 & (0.78 to 0.88$)$ & 0.84 & $(0.78$ to 0.90$)$ \\
\hline 3rd quartile & 0.71 & (0.65 to 0.79$)$ & 0.73 & (0.68 to 0.79$)$ & 0.71 & (0.67 to 0.75$)$ & 0.70 & (0.65 to 0.75$)$ \\
\hline 4th quartile & 0.57 & (0.51 to 0.63$)$ & 0.59 & (0.55 to 0.64$)$ & 0.62 & (0.58 to 0.66$)$ & 0.61 & (0.57 to 0.66$)$ \\
\hline $\mathrm{P}$ trend & $<0.001$ & & $<0.001$ & & $<0.001$ & & $<0.001$ & \\
\hline
\end{tabular}

Models for exposure-effect lags of $0,1,2$ and 3 years.

*IRR adjusted for variables specified in the table plus age, sex and year of discharge as a random-effect variable. Four independent models, each including the variable of interest on a categorical scale adjusted for the others on a continuous scale.

†DHDs: Number of Defined Daily Doses per 1000 inhabitants per day.

DHD, defined daily doses; IRRs, incidence rate ratios.

incidence in the recent years of the study is not accounted for by the factors analysed, indicating, in turn, that this may be due to the decline in passive smoking, resulting not only from the cumulative reduction in active smoking itself in the years preceding the entry into force of these measures, but also from the direct impact of the first Antismoking Act. Different studies undertaken in Spain ${ }^{33} 34$ and other countries ${ }^{12} 13$ have shown the effect on IHD mortality and morbidity of a legal ban on smoking in the workplace.

The results support a primary prevention strategy based on pharmacological control of vascular risk. Evidence of the effectiveness of this strategy at a population level, which implies the mass use of medication, is especially important in an adverse economic context, and more so when the use of drugs for cardiovascular
Figure 2 Time series of incidence analysed using non-parametric generalised additive models. Left plot: smoothed series adjusted for age and sex. Right plot: smoothed series adjusted for age, sex, prevalence of smoking, obesity and overweight, and use of cardiovascular disease prevention drug therapy. Solid lines represent the incidence rate ratios (IRRs) and dashed lines are the upper and lower limits of its $95 \% \mathrm{Cl}$.
IRR

IRR
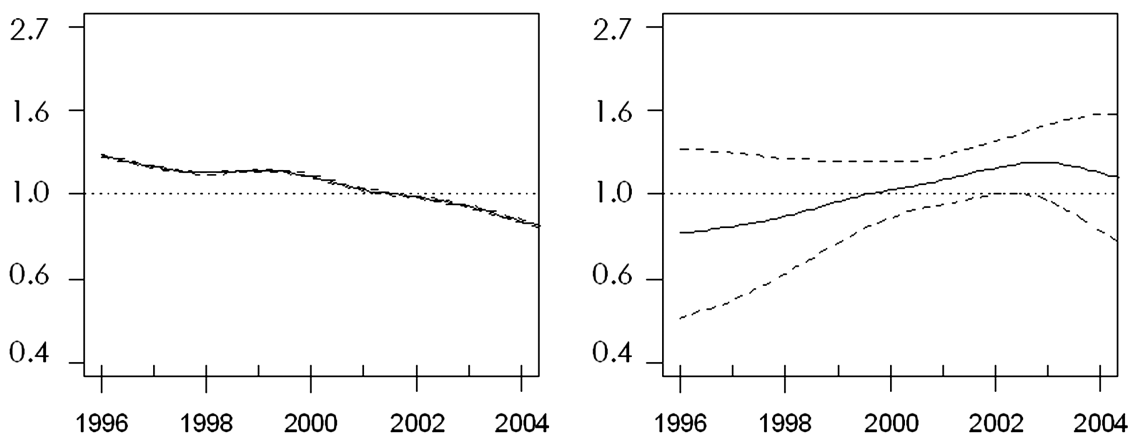

Year of hospital discharge 
disease prevention in healthy persons has been the subject of controversy. ${ }^{35}$ Specifically, in the case of the various statins, meta-analyses of clinical trials have yielded contradictory results, ${ }^{36-40}$ with some authors being of the opinion that it is preferable to change the lifestyles of these patients. While this study does not purport to assess the clinical effect of these drugs, its results, nonetheless, show a statistically significant decrease in the age-adjusted and sex-adjusted hospitalisation rate associated with the use of statins and hypertensive, antiplatelet and antidiabetic drugs. Although the presence of strong collinearity ruled out any analysis of the independent effect of each of these drugs with adjustment for remainder, their use considered jointly did show a strong protective effect, regardless of the effect of sex, age, smoking prevalence and excessive weight, a finding in line with the consideration that vascular risk is multifactorial and cannot be corrected by controlling the respective risk factors in isolation. ${ }^{7}$ The appropriate balance between economic and health objectives by policies aimed at reducing pharmaceutical costs, such as those fostering the use of generic drugs or a gradual reduction in profit margins for producers and distributors, ${ }^{41}$ has been a decisive factor in this public health success. However, recent studies reveal that there is still much room for improvement in the detection, treatment and control of vascular risk. ${ }^{31}$

In contrast with smoking and control of vascular risk, prevalences of overweight and obesity, positively associated with incident IHD hospitalisation rates, increased across the study period, indicating that prevention based on promoting a healthy diet and physical exercise and changing obesogenic lifestyles is proving inadequate or ineffective, probably because the effects of these policies will only be seen in the longer term. ${ }^{10}$ Without ignoring smoking prevention or therapeutic control of vascular risk, our results indicate that, from a public health stance, treatment and prevention of excess weight should be made a priority. Community interventions aimed at changing the prevalence of obesity and sedentarism are multidisciplinary, going beyond the strict scope of healthcare and involving multiple levels, such as education, the food sector, town planning and administration, provision of sports facilities, transport policy, etc. ${ }^{11}$ Moreover, with the change of lifestyles, many treatments could be avoided-and in this respect, our sympathies are with those who advocate this-but, until such a time as a cost-effective means of changing the prevalence of obesity and sedentarism becomes available, the use of vascular prevention drug therapy is an inevitable strategy.

In the correct interpretation of the results of this study, some limitations must be borne in mind. First, this study was based on health indicators and targeted at the assessment of public health; its results should not be extrapolated to the clinical sphere, that is, to the clinical management of individual patients, and are thus not interpretable as outcomes of clinical or intervention trials, even though they may nuance the latter to the extent they provide an illustration of their external validity. Second, the results are exclusively applicable to cases of hospitalised incident IHD; having said this, however, the possibility that the decline in hospitalisations might be due to increases in preadmission mortality can be conclusively ruled out because mortality rates due to sudden death or poorly defined causes not only decreased across the study period but they actually decreased to a greater extent. ${ }^{2}$ Errors of measurement that are inherent in the ecological design and limit causal inference are of little relevance in this study, in view of the fact that, in all the factors considered, causality was clearly shown. Identification of incident cases was based on an estimate but the method used was validated, with high sensitivity and specificity values being obtained. What is more, the proportion of cases of acute infarction with previous clinical history in our series (26.6\%) agrees with the results of the PRIAMHO II Registry, ${ }^{42}$ in which $24 \%$ of cases were shown to have a history of previous infarction or revascularisation.

The remaining potential study limitations stem from the nature of the available data and, were they to have some impact, would in all cases bias the results towards the null hypothesis and so tend to underestimate the effect. With respect to the exposure data studied, these were drawn from a self-report questionnaire without any objective measures of smoking, weight and height; and, while self-reported smoking data are regarded as valid, those on obesity and overweight may be underestimated. The data relating to drug use refer to total use: these drugs are prescribed not only for primary prevention, but also for secondary prevention and treatment of other conditions, such as arrhythmias and heart failure. Nevertheless, the frequency of these diseases is infinitely lower than the prevalence of vascular risk in the general adult population, and is, indeed, almost negligible in comparison. At all events, the error would, yet again, tend more towards overestimating exposure and, by extension, underestimating the effect. Finally, specific dietary factors (ie, fish, vegetables or alcoholic beverages), nutritional factors (ie, fats) and physical activity factors were not analysed for reasons of parsimony; instead, the frequency of obesity and overweight was used as an indicator of quality of diet and physical activity as a whole.

In conclusion, after decades of continuous rises, incidence of IHD hospitalisation fell from 1997 onwards, a decline that was associated with the decrease in smoking and, in equal measure, with the increase in vascular risk drug therapy. The cumulative decline of $52 \%$ over 13 years might have been even greater if there had not been a concomitant increase in the prevalence of excessive weight, also associated with incidence. These results indicate that current IHD primary prevention strategies have been effective at a population level, thanks to an appropriate balance between financial and health goals, something that should be left intact despite the current 
economic crisis. Future strategies should lay special stress on the prevention and treatment of excessive weight.

Acknowledgements The authors would like to thank Michael Benedict for his help with the English version of the manuscript.

Contributors MJM conceived the study, its design and coordinated the research team. MJM, EA-C, CO and IG performed the statistical analysis and interpretation of data and prepared the draft manuscript. All authors participated in the design of the study and in critical review of the manuscript. All authors read and approved the final manuscript.

Funding This study was supported by Independent Clinical Research grant EC11-282 from the Ministry of Health, Social Services \& Equality.

Competing interests None.

Provenance and peer review Not commissioned; externally peer reviewed.

Data sharing statement Technical appendix and supplementary material are available online. Individual patient datasets are protected by Spanish regulations; these may be obtained from the Spanish Ministry of Health and the National Institute of Statistics under specific data loan agreements.

Open Access This is an Open Access article distributed in accordance with the Creative Commons Attribution Non Commercial (CC BY-NC 3.0) license, which permits others to distribute, remix, adapt, build upon this work noncommercially, and license their derivative works on different terms, provided the original work is properly cited and the use is non-commercial. See: http:// creativecommons.org/licenses/by-nc/3.0/

\section{REFERENCES}

1. Marrugat J, Elosua R, Aldasoro E, et al. Regional variability in population acute myocardial infarction cumulative incidence and mortality rates in Spain 1997 and 1998. Eur J Epidemiol 2004;19:831-9.

2. Instituto Nacional de Estadística. Defunciones según la causa de muerte. Madrid: INE. http://www.ine.es/jaxi/menu.do? type=pcaxis\&path=/t15/ p417\&file=inebase\&L=0 (accessed 23 May 2013).

3. Medrano-Albero MJ, Boix-Martinez R, Cerrato-Crespan E, et al. [Incidence and prevalence of ischaemic heart disease and cerebrovascular disease in Spain: a systematic review of the literature]. Rev Esp Salud Publica 2006;80:5-15.

4. Madrid: Ministerio de Sanidad y Consumo. Estrategia frente a la Cardiopatía Isquémica del Sistema Nacional de Salud. 2006.

5. Brotons C, Royo-Bordonada MA, Alvarez-Sala L, et al. [Spanish adaptation of the European Guidelines on Cardiovascular Disease Prevention]. Rev Esp Salud Publica 2004;78:435-8.

6. Graham I, Atar D, Borch-Johnsen K, et al. Guías de práctica clínica sobre prevención de la enfermedad cardiovascular: versión resumida. Rev Esp Cardiol 2008;61:e1-49.

7. Pearson TA, Blair SN, Daniels SR, et al. AHA guidelines for primary prevention of cardiovascular disease and stroke: 2002 update: Consensus Panel Guide to Comprehensive Risk Reduction for Adult Patients without Coronary or Other Atherosclerotic Vascular Diseases. American Heart Association Science Advisory and Coordinating Committee. Circulation 2002;106:388-91.

8. Marrugat J, D'Agostino R, Sullivan L, et al. An adaptation of the Framingham coronary heart disease risk function to European Mediterranean areas. J Epidemiol Community Health 2003;57:634-8.

9. Conroy RM, Pyorala K, Fitzgerald AP, et al. Estimation of ten-year risk of fatal cardiovascular disease in Europe: the SCORE project. Eur Heart J 2003;24:987-1003.

10. Ballesteros Arribas JM, Dal-Re Saavedra M, Perez-Farinos N, et al. [The Spanish strategy for nutrition, physical activity and the prevention of obesity (NAOS Strategy)]. Rev Esp Salud Publica 2007;81:443-9.

11. World Health Organization. The challenge of obesity in the WHO European Region and the strategies for response. Copenhagen, Denmark Europe, 2007. http://www.euro.who.int/_data/assets/pdf file/0010/74746/E90711.pdf (accessed 23 May 2013).

12. Tan CE, Glantz SA. Association between smoke-free legislation and hospitalizations for cardiac, cerebrovascular, and respiratory diseases: a meta-analysis. Circulation 2012;126:2177-83.
13. Dove MS, Dockery DW, Mittleman MA, et al. The impact of Massachusetts' smoke-free workplace laws on acute myocardial infarction deaths. Am J Public Health 2010;100:2206-12.

14. Rothwell PM. External validity of randomised controlled trials: 'to whom do the results of this trial apply?'. Lancet 2005 365:82-93.

15. Ford ES, Ajani UA, Croft JB, et al. Explaining the decrease in US deaths from coronary disease, 1980-2000. N Engl J Med 2007:356:2388-98.

16. Laatikainen T, Critchley J, Vartiainen E, et al. Explaining the decline in coronary heart disease mortality in Finland between 1982 and 1997. Am J Epidemiol 2005;162:764-73.

17. Capewell S, Beaglehole R, Seddon M, et al. Explanation for the decline in coronary heart disease mortality rates in Auckland, New Zealand, between 1982 and 1993. Circulation 2000 102:1511-16.

18. Unal B, Critchley JA, Capewell S. Explaining the decline in coronary heart disease mortality in England and Wales between 1981 and 2000. Circulation 2004;109:1101-7.

19. Bjorck L, Rosengren A, Bennett K, et al. Modelling the decreasing coronary heart disease mortality in Sweden between 1986 and 2002. Eur Heart J 2009;30:1046-56.

20. Palmieri L, Bennett K, Giampaoli S, et al. Explaining the decrease in coronary heart disease mortality in Italy between 1980 and 2000 Am J Public Health 2010;100:684-92.

21. Flores-Mateo G, Grau M, O'Flaherty M, et al. [Analyzing the coronary heart disease mortality decline in a Mediterranean population: Spain 1988-2005]. Rev Esp Cardiol 2011;64:988-96.

22. Yeh RW, Sidney S, Chandra M, et al. Population trends in the incidence and outcomes of acute myocardial infarction. $N$ Engl $J$ Med 2010;362:2155-65.

23. Chen J, Normand SL, Wang Y, et al. Recent declines in hospitalizations for acute myocardial infarction for Medicare fee-for-service beneficiaries: progress and continuing challenges Circulation 2010;121:1322-8.

24. Barchielli A, Balzi D, Naldoni P, et al. Hospital discharge data for assessing myocardial infarction events and trends, and effects of diagnosis validation according to MONICA and AHA criteria. $J$ Epidemiol Community Health 2012;66:462-7.

25. Briffa T, Nedkoff L, Peeters A, et al. Discordant age and sex-specific trends in the incidence of a first coronary heart disease event in Western Australia from 1996 to 2007. Heart 2011;97:400-4.

26. Shalev V, Goldshtein I, Porath A, et al. Continuation of statin therapy and primary prevention of nonfatal cardiovascular events. Am J Cardiol 2012;110:1779-86.

27. Agencia Española de Medicamentos y Productos Sanitarios. Informes del Observatorio de Uso de Medicamentos. Madrid: AEMPS. http://www.aemps.gob.es/medicamentosUsoHumano/ observatorio/informes.htm (accessed 23 Aug 2012).

28. Ministerio de Sanidad Política Social e Igualdad. Portal Estadístico del SNS. Madrid: MSSSI. http://www.msssi.gob.es/estadEstudios/ estadisticas/sisInfSanSNS/home.htm (accessed 23 Aug. 2012).

29. R: A language and environment for statistical computing [computer program]. Version 2.15.0. Vienna, Austria: R Foundation for Statistical Computing, 2012.

30. Alpert JS, Thygesen K, Antman E, et al. Myocardial infarction redefined-a consensus document of the Joint European Society of Cardiology/American College of Cardiology Committee for the redefinition of myocardial infarction. J Am Coll Cardiol 2000;36:959-69.

31. Grau M, Elosua R, Cabrera de Leon A, et al. [Cardiovascular risk factors in Spain in the first decade of the 21st Century, a pooled analysis with individual data from 11 population-based studies: the DARIOS study]. Rev Esp Cardiol 2011;64:295-304.

32. Ministerio de Sanidad Política Social e Igualdad. Protección de la salud: tabaco. Legislación, índice cronológico. Madrid: MSSSI. http:// www.msssi.gob.es/ciudadanos/proteccionSalud/tabaco/legislacion. htm (accessed 23 May 2013).

33. Villalbi JR, Sanchez E, Benet J, et al. The extension of smoke-free areas and acute myocardial infarction mortality: before and after study. BMJ Open 2011;1:e000067.

34. Agüero F, Degano IR, Subirana I, et al. Impact of a partia smoke-free legislation on myocardial infarction incidence, mortality and case-fatality in a population-based registry: the REGICOR Study. PLOS ONE 2013;8:e53722.

35. Redberg RF, Katz MH. Healthy men should not take statins. JAMA 2012;307:1491-2.

36. Brugts JJ, Yetgin T, Hoeks SE, et al. The benefits of statins in people without established cardiovascular disease but with cardiovascular risk factors: meta-analysis of randomised controlled trials. BMJ 2009;338:b2376. 
37. Ray KK, Seshasai SR, Erqou S, et al. Statins and all-cause mortality in high-risk primary prevention: a meta-analysis of 11 randomized controlled trials involving 65,229 participants. Arch Intern Med 2010;170:1024-31.

38. Taylor F, Ward K, Moore TH, et al. Statins for the primary prevention of cardiovascular disease. Cochrane Database Syst Rev 2011;(1): CD004816.

39. Thavendiranathan $\mathrm{P}$, Bagai A, Brookhart MA, et al. Primary prevention of cardiovascular diseases with statin therapy: a meta-analysis of randomized controlled trials. Arch Intern Med 2006;166:2307-13.
40. Vrecer M, Turk S, Drinovec J, et al. Use of statins in primary and secondary prevention of coronary heart disease and ischemic stroke. Meta-analysis of randomized trials. Int $J$ Clin Pharmacol Ther 2003:41:567-77.

41. Ministerio de Sanidad Política Social e Igualdad. Economía del Medicamento y Productos Sanitarios. Madrid: MSSSI. http://www. msssi.gob.es/profesionales/farmacia/legislacion/economia/home.htm (accessed 26 May 2013).

42. Aros F, Cunat J, Loma-Osorio A, et al. [Management of myocardial infarction in Spain in the year 2000. The PRIAMHO II study]. Rev Esp Cardiol 2003;56:1165-73. 